\title{
Impedance Spectroscopic Study of p-i-n Type a-Si Solar Cell by Doping Variation of p-Type Layer
}

\author{
Sunhwa Lee, ${ }^{1}$ Seungman Park, ${ }^{1}$ Jinjoo Park, ${ }^{1}$ Youngkuk Kim, ${ }^{1}$ \\ Hyeongsik Park, ${ }^{1}$ Juyeun Jang, ${ }^{1}$ Chonghoon Shin, ${ }^{2}$ Youn-Jung Lee, ${ }^{1}$ \\ Seungsin Baek, ${ }^{1}$ Minbum Kim, ${ }^{2}$ Junhee Jung, ${ }^{2}$ and Junsin Yi ${ }^{1,2}$ \\ ${ }^{1}$ School of Information and Communication Engineering, Sungkyunkwan University, Suwon 440-746, Republic of Korea \\ ${ }^{2}$ Department of Energy Science, Sungkyunkwan University, Suwon 440-746, Republic of Korea \\ Correspondence should be addressed to Junsin Yi, yi@yurim.skku.ac.kr
}

Received 30 August 2011; Revised 1 February 2012; Accepted 12 February 2012

Academic Editor: C. W. Lan

Copyright () 2012 Sunhwa Lee et al. This is an open access article distributed under the Creative Commons Attribution License, which permits unrestricted use, distribution, and reproduction in any medium, provided the original work is properly cited.

We investigated $\mathrm{p}$-i-n type amorphous silicon $(\mathrm{a}-\mathrm{Si})$ solar cell where the diborane flow rate of the p-type layer was varied and the solar cell was measured static/dynamic characteristics. The p/i interface of the thin film amorphous silicon solar cells was studied in terms of the coordination number of boron atoms in the p layer. p-type layer and p/i interface properties were obtained from the X-ray photoelectron spectroscopy (XPS) and impedance spectroscopy. One of the solar cells shows open circuit voltage $\left(V_{\text {oc }}\right)=880 \mathrm{mV}$, short circuit current density $\left(J_{\mathrm{sc}}\right)=14.21 \mathrm{~mA} / \mathrm{cm}^{2}$, fill factor $(\mathrm{FF})=72.03 \%$, and efficiency $(\eta)=8.8 \%$ while the p-type layer was doped with $0.1 \%$. The impedance spectroscopic measurement showed that the diode ideality factor and built-in potential changed with change in diborane flow rate.

\section{Introduction}

In a-Si:H-based $\mathrm{p}$-i-n type solar cells, the device performance is limited by various factors, most important of which is defects in the p-layer and that in the p/i interface. The electron-hole pair, generated in the i-type layer, is collected by the $n$-type and p-type layers. Thus effective doping of these extrinsic layers is very important in creating the builtin field so that the photo-generated charge carriers are efficiently collected. At the p/i interface there exists a depletion region, a similar depletion layer also exist at the $\mathrm{n} / \mathrm{i}$ interface. These two depletion regions create localized capacitors, formed by the outer layers of the depletion regions. As the depletion region is free from charge carriers so the defects in these regions become electronically more active. The photogenerated carriers, that pass through the depletion region, will most probably face hindrance in their movement or effective resistance faced by the charge carriers will become high. An impedance spectroscopic measurement can help exploring the interface characteristics to some extent.
We performed impedance spectroscopic measurement of the solar cells that have similar i-type and n-type layers but the doping ratio for the p-type layer was different. The p-type layers of these cells were deposited by increasing diborane doping ratio during its deposition. The impedance spectroscopic analysis was performed by following Cole-Cole principle $[1,2]$ in which the real and imaginary components of the complex impedance $(Z)$ are plotted for various sinusoidal input signals. Impedance spectroscopy is particularly suitable for studying the properties of junctions, interfaces, and contacts. The $\mathrm{p} / \mathrm{i}$ interface properties were obtained from the static/dynamic characteristics. The experimental details are given in the following.

\section{Experimental}

Hydrogenated a-Si solar cells were deposited in a cluster type radio frequency $(\mathrm{RF})$ plasma-enhanced chemical vapor deposition (PECVD), with the RF of $13.56 \mathrm{MHz}$ (for both player and n-layer) and very high frequency of $60 \mathrm{MHz}$ (for 


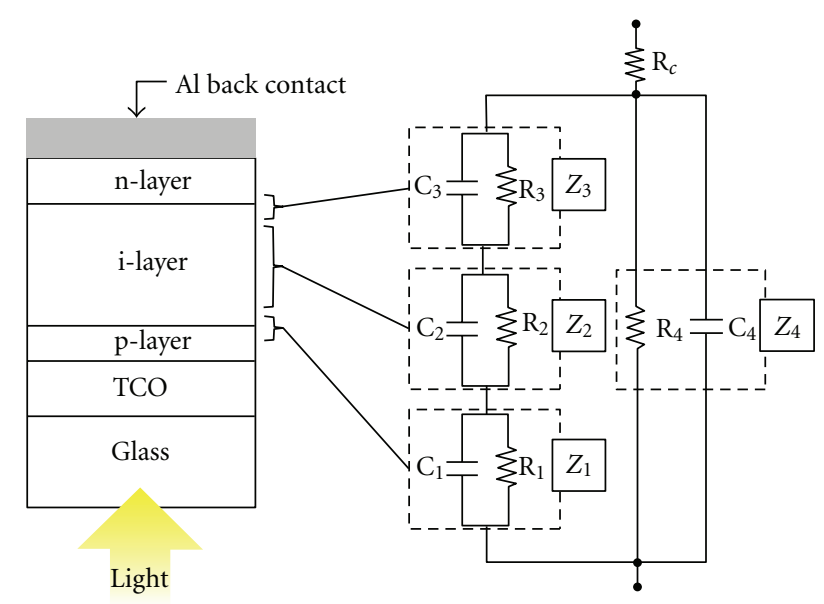

FIgURE 1: Equivalent circuit diagram of solar cell impedances, formed by a combination of resistors and capacitors.

the i-layer) power source. Prior to deposition, the glass substrates were ultrasonically cleaned by dipping in acetone, isopropyl alcohol, and deionized (DI) water for $10 \mathrm{~min}$. The sample deposition conditions for the $\mathrm{p}$-type layers are summarized in Table 1. The devices were deposited on TCOcoated glasses (Asahi VU-glass).

The boron doping ratio was varied by changing the flow rate of $\mathrm{B}_{2} \mathrm{H}_{6}$. The optoelectronic properties of these films were measured. Spectroscopic ellipsometry (VASE, J. A. Woollam, $240 \mathrm{~nm}<\lambda<1700 \mathrm{~nm}$ ) was used to measure the thickness, refractive index, absorption coefficient, and optical band gap at an angle of incidence of $65^{\circ}$ in the spectral range of $240 \mathrm{~nm}$ to $1700 \mathrm{~nm}$. The electrical characteristics were studied by the coplanar method using programmable Keithley 617 electrometer using the samples grown on the glass substrates.

The current-voltage $(I-V)$ characteristics of the cells were measured under light intensity of $100 \mathrm{~mW} / \mathrm{cm}^{2}$ (AM1.5), at a temperature of $25^{\circ} \mathrm{C}$. The impedance measurement was carried out using 4192A LF impedance analyzer. The amplitude of the ac test signal was $10 \mathrm{mV}$. The measurement frequency was in the range of $1 \mathrm{~Hz}$ to $1 \mathrm{MHz}$.

\section{Model}

We adopt the following assumptions in order to limit our scope of impedance analysis to a few important parameters we are interested in.

(1) We assume the cell has three interfaces of importance, having a combination of resistor-capacitor connected in parallel to each of the interfaces, as shown in Figure 1.

(2) The TCO/p-layer interface does not significantly influence total capacitance of the cell, so we assume that the depletion capacitances at $\mathrm{p} / \mathrm{i}$ interface, $\mathrm{i}$ bulk, and $\mathrm{i} / \mathrm{n}$-interface are significant in our study.

Based on the above assumptions we draw the equivalent circuit diagram of the impedance of the solar cell, as shown in
Figure 1. The model will help us simplifying the impedance analysis of the Cole-Cole plot.

\section{Results and Discussions}

In the following we give results and discussions on the effect of boron doping on the p-type material, characteristics of the solar cells, and its impedance analysis. These p-type a-Si: H materials while used in solar cell is expected to show useful photovoltaic characteristics.

4.1. Effect of $\mathrm{B}_{2} \mathrm{H}_{6}$ Doping on p-Type Layer. The B(1s) XPS peak of pure boron appears at a binding energy of $188 \mathrm{eV}$. It bonds with $\mathrm{Si}$ and shifts to a lower energy state. Figure 2 shows the total B(1s) XPS peak (a) and the deconvoluted $\mathrm{B}$ (1s) XPS peak (b). The $186.6 \mathrm{eV}$ represents a threefold coordination and the $187.7 \mathrm{eV}$ a fourfold coordination [3]. The result of the deconvolution analysis, assuming Gaussian functions shows that the boron atoms in the states of both the three- and fourfold coordination increased with the increase of the diborane flow rate. When $\mathrm{B}_{2} \mathrm{H}_{6}, \mathrm{SiH}_{4}$, and $\mathrm{H}_{2}$ form a bonding, the boron existed in the state of an inactive threefold coordination and an active fourfold coordination. As the diborane flow rate increased, the fourfold coordination that contributed to the dark conductivity also increased. Increasing the fourfold coordination led to an increase of the positively charged dangling bonds by the " $8-\mathrm{N}$ " doping rule $[4,5]$.

Figure 3 shows dark conductivity $\left(\sigma_{\mathrm{d}}\right)$ and activation energy $\left(E_{\mathrm{a}}\right)$ at various doping level. At increased doping the conductivity increases and the activation energy decreases, a change as expected from the change of coordination [6]. The dark conductivity of the p-type layer was measured in planar electrode configuration. The activation energy $\left(E_{\mathrm{a}}\right)$ was obtained from the temperature-dependent dark conductivity $\sigma_{\mathrm{d}}(T)$ measurement, following the Arrhenius relation

$$
\sigma_{\mathrm{d}}(T)=\sigma_{\mathrm{o}} \exp \left(-\frac{E_{\mathrm{a}}}{k T}\right),
$$

where $\sigma_{\mathrm{o}}$ is a conductivity prefactor, $T$ the absolute temperature, and $k$ Boltzmann's constant. Table 3 shows the characteristic optoelectronic properties of the three layers of the solar cell. The increase in diborane flow rate during deposition of the p-type layer leads to a change in optical absorption spectra of the films, as observed by spectroscopic ellipsometry (SE) measurement. Optical band gap $\left(E_{\mathrm{g}}\right)$ was measured using these absorption coefficients and Tauc's formula

$$
(\alpha h \nu)^{1 / 2}=K\left(h \nu-E_{\mathrm{g}}\right),
$$

where $h$ is Plank's constant, $v$ is optical frequency, and $K$ is a constant. Optical absorption coefficients of the films, $\alpha$, is measured with the help of spectroscopic ellipsometry (SE), and $(\alpha h \nu)^{1 / 2}$ is plotted with $h v$. A linear fit is drawn at the absorption edge region and the intercept of the linear fitting is used as a measure of $E_{\mathrm{g}}$.

It shows that the $E_{\mathrm{g}}$ and $E_{\mathrm{a}}$ of the p-layer decrease with increasing diborane flow rate, this is a usual phenomena [7-9]. 


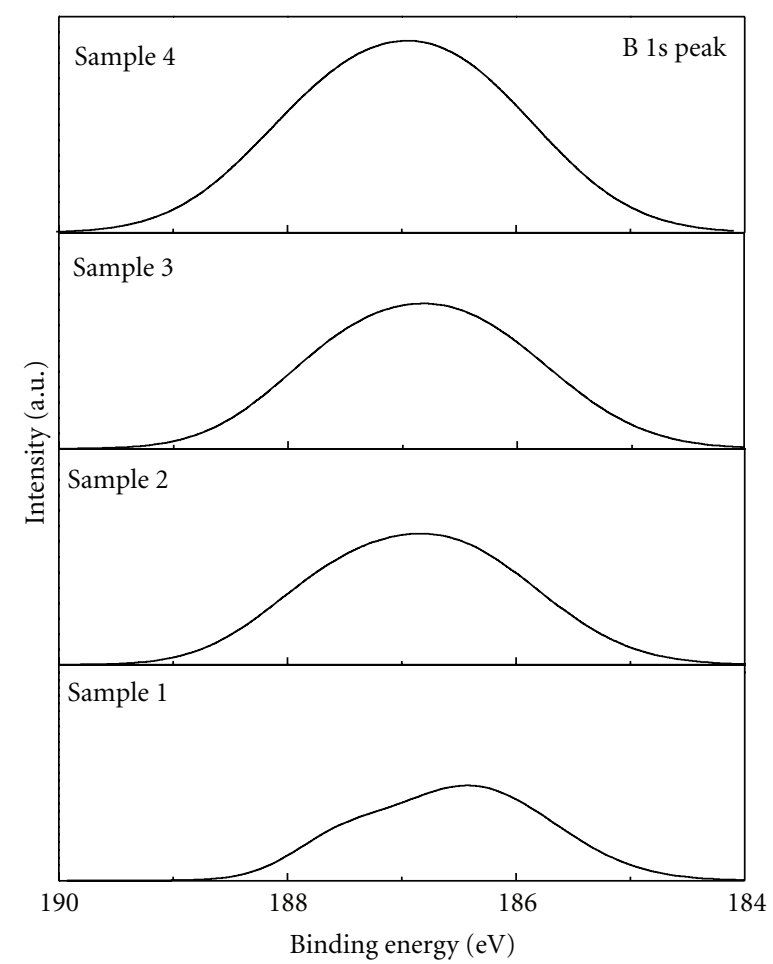

(a)

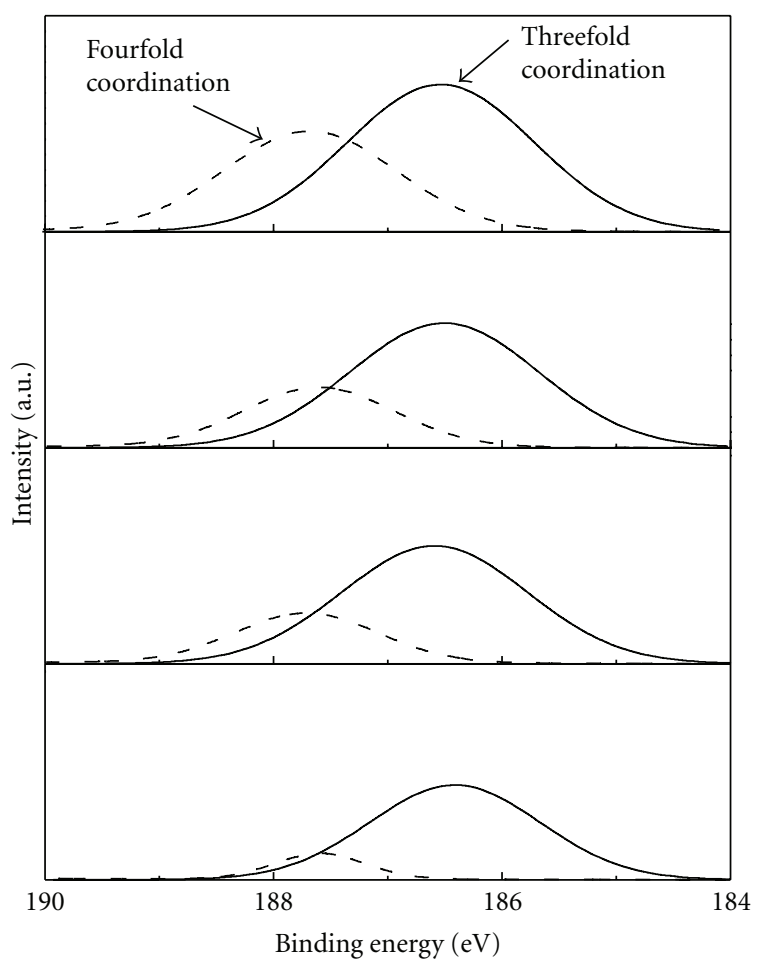

(b)

FIGURE 2: XPS spectrum of the B(1s) signal of the boron-doped amorphous silicon layers. It is deconvoluted into two Gaussian peaks, as shown in (b).

TABLE 1: The deposition conditions for the p-type a-Si: H layers.

\begin{tabular}{|c|c|c|c|c|c|c|c|}
\hline \multirow{2}{*}{ Sample } & \multicolumn{3}{|c|}{ Gas ratio } & \multirow{2}{*}{ Thickness (nm) } & \multirow{2}{*}{ Power density $\left(\mathrm{mW} / \mathrm{cm}^{2}\right)$} & \multirow{2}{*}{ Temp. $\left({ }^{\circ} \mathrm{C}\right)$} & \multirow{2}{*}{ Pressure (mTorr) } \\
\hline & $\mathrm{SiH}_{4}$ & $\mathrm{H}_{2}$ & $\mathrm{~B}_{2} \mathrm{H}_{6}$ & & & & \\
\hline 1 & \multirow{4}{*}{1} & \multirow{4}{*}{5} & 0.05 & \multirow{4}{*}{150} & \multirow{4}{*}{50} & \multirow{4}{*}{175} & \multirow{4}{*}{200} \\
\hline 2 & & & 0.1 & & & & \\
\hline 3 & & & 0.3 & & & & \\
\hline 4 & & & 0.5 & & & & \\
\hline
\end{tabular}

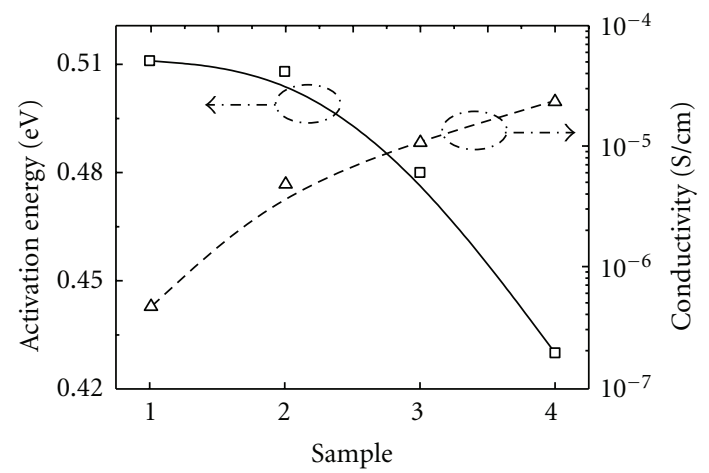

FIGURE 3: Dark conductivity and activation energy of p-type a-Si : $\mathrm{H}$ prepared at various $\mathrm{B}_{2} \mathrm{H}_{6}$ flow rates.

4.2. Effect of $B_{2} H_{6}$ Doping on Solar Cell. The current-voltage characteristics of the solar cell under light is shown in
Figure 4. We have observed an initial improvement in solar cell characteristics in sample 2 from that of sample 1 but afterwards the solar cell characteristics degrade in FF, $J_{\mathrm{sc}}, V_{\mathrm{oc}}$, and $\eta$. For sample 2 these values are $J_{\mathrm{sc}}=14.21 \mathrm{~mA} / \mathrm{cm}^{2}$, $V_{\mathrm{oc}}=870 \mathrm{mV}, \eta=8.8 \%$, and fill factor $(\mathrm{FF})=71.51 \%$.

As it is expected that higher $\mathrm{B}_{2} \mathrm{H}_{6}$ flow rate will make the p-type layer increasingly doped, it is expected that it will help creating higher built-in potential at the $\mathrm{p} / \mathrm{i}$ interface, resulting in better collection of electron-hole pairs by the ntype and p-type layer of the solar cell and improved solar cell characteristics. However, as diborane flow rate increases, the defects in the p-layer and p/i interface also increase. The open circuit voltage and fill factor decreased from $880 \mathrm{mV}$ to $800 \mathrm{mV}, 72 \%$ to $69 \%$ with three- and fourfold coordination increased from sample 2 to sample 4 . The defects in the $\mathrm{p}$ type window layer also increased because boron atoms coordination usually produces doping-induced defects $[4,5]$. These increases in the defect resulted in a carrier recombination near the $\mathrm{p} / \mathrm{i}$ interface and caused the reduction 


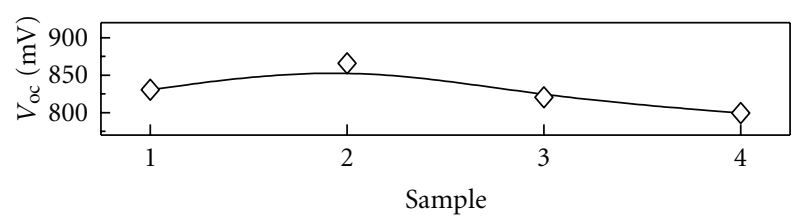

(a)

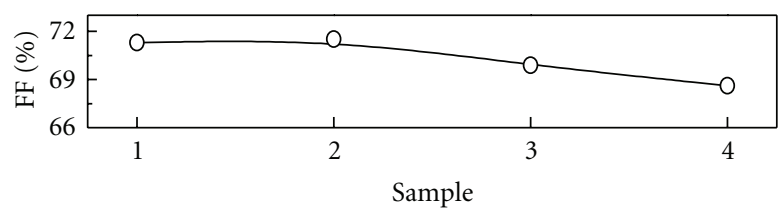

(c)

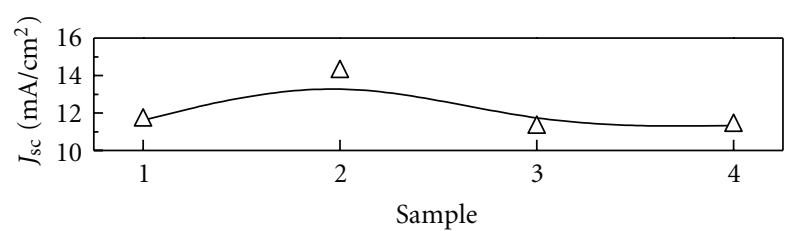

(b)

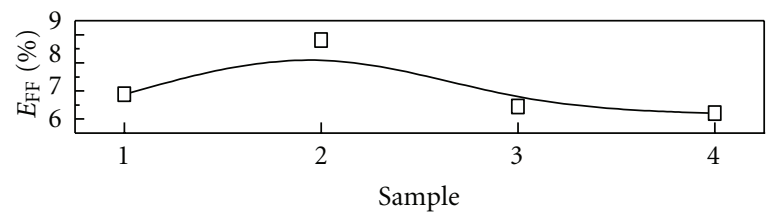

(d)

FIGURE 4: Solar cell parameters measured under AM 1.5 illumination conditions of thin film solar cells, with p-layer having different doping ratio.

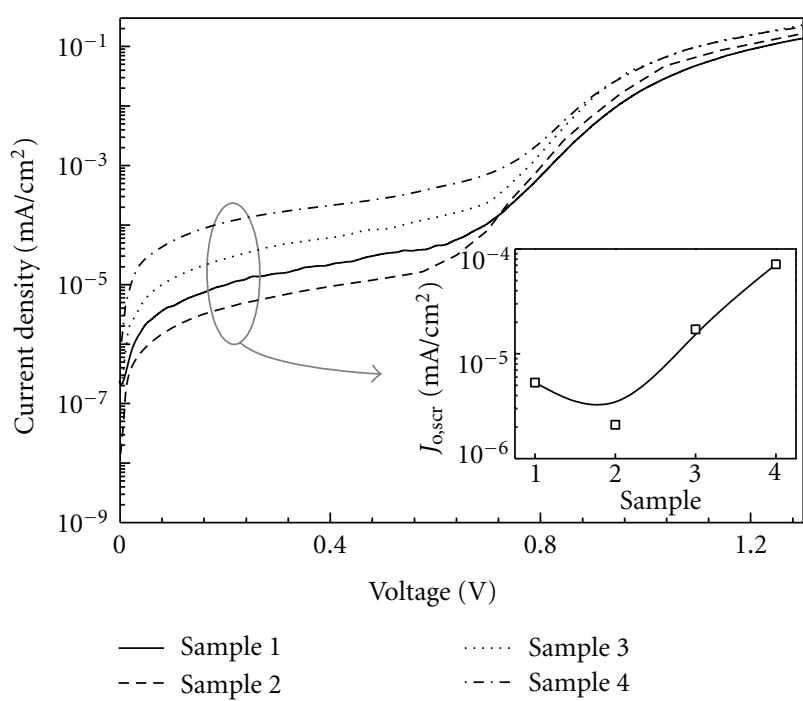

FIGURE 5: Far forward bias dark $J-V$ characteristics for a-Si thin film solar cells at various $\mathrm{B}_{2} \mathrm{H}_{6}$ flow rates.

in $V_{\text {oc }}$ and FF of the highly doped $\mathrm{p}$ type window layer with an increase in the saturation current density of the spacecharge region $[10,11]$.

The saturation current density, $J_{0}$, obtained by fitting the dark $I-V$ curve to the two diode model in the spacecharge region and in the quasineutral region. The spacecharge region is mostly affected by the interface, while the quasineutral region is influenced by the bulk. Figure 5 shows dark $J-V$ characteristics of a-Si thin film solar cells at different boron atoms bonding coordinations. With a further increase in three- and fourfold coordinated bonding, the saturation current of a-Si thin film solar cells increased from $2.10 \times 10^{-6}$ to $7.14 \times 10^{-5} \mathrm{~mA} / \mathrm{cm}^{2}$. It may also be due to doping-induced defects. Increase of the saturation current indicates increase in carrier recombination which can be related to the decrease in $V_{\text {oc }}$ as well as FF. In order to investigate this following impedance spectroscopic measurements have been performed.

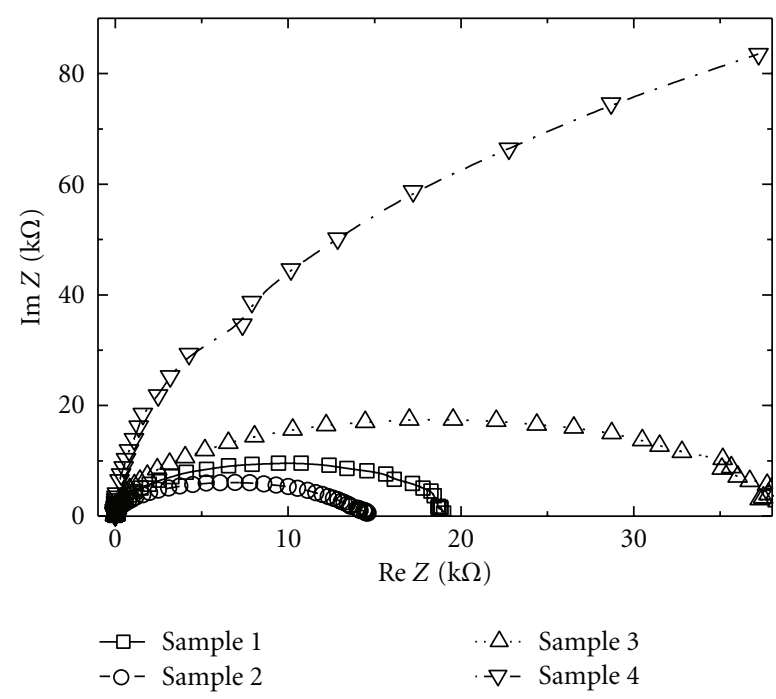

Figure 6: Cole-Cole plot of a-Si solar cell having different p-type layers, under zero DC bias.

4.3. Effect of $\mathrm{B}_{2} \mathrm{H}_{6}$ Doping on p/i-Interface Capacitance. Figure 6 shows the Cole-Cole type plot for the measured impedance $(Z)$ of the cell under $10 \mathrm{mV}$ amplitude sinusoidal potential (AC field), where the $Z$ is the complex AC impedance of the cell. The estimated AC parameters are shown in Table 4. The frequency of impedance and the maximum value of $y$-axis are given by

$$
\omega=2 \pi f=\frac{1}{R_{\mathrm{p}} C_{\mathrm{p}}}, \quad Z_{\max }^{\prime \prime}=\frac{R_{\mathrm{p}}}{2} .
$$

Series resistance $\left(R_{\mathrm{s}}\right)$ can be obtained from intercept of the trace with real axis in the high-frequency region, and the total resistance, $R_{\mathrm{s}}+R_{\mathrm{p}}$ is indicated from the low-frequency region [12].

It shows the total diffusion capacitance $\left(C_{\mathrm{d}}\right)$ and resistance of the cell, however, as the observed change is because of the change in the doping of the p-type layer so we consider the change as because of the $\mathrm{p} / \mathrm{i}$ depletion capacitance $\left(C_{1}\right)$ 
TABLE 2: Deposition condition of solar cell layers.

\begin{tabular}{|c|c|c|c|c|c|c|c|c|}
\hline \multirow{2}{*}{ Layer } & \multicolumn{4}{|c|}{ Gas ratio } & \multirow{2}{*}{ Thickness (nm) } & \multirow{2}{*}{ Power density $\left(\mathrm{mW} / \mathrm{cm}^{2}\right)$} & \multirow{2}{*}{ Temp. $\left({ }^{\circ} \mathrm{C}\right)$} & \multirow{2}{*}{ Pressure (mTorr) } \\
\hline & $\mathrm{SiH}_{4}$ & $\mathrm{H}_{2}$ & $\mathrm{~B}_{2} \mathrm{H}_{6}$ & $\mathrm{PH}_{3}$ & & & & \\
\hline $\mathrm{p}$ & 1 & 5 & $0.05 \sim 0.5$ & & 15 & 50 & 175 & 200 \\
\hline $\mathrm{i}$ & 1 & 1 & & & 350 & 42 & 180 & 200 \\
\hline $\mathrm{n}$ & 1 & 5 & & 1 & 25 & 70 & 200 & 200 \\
\hline
\end{tabular}

TABLE 3: Characteristic properties of the layers of solar cell, where $\sigma_{\mathrm{ph}}\left(\mathrm{S} \cdot \mathrm{cm}^{-1}\right)$ is photo conductivity.

\begin{tabular}{lcccc}
\hline Layer & $E_{\mathrm{g}}(\mathrm{eV})$ & $\sigma_{\mathrm{d}}\left(\mathrm{S} \cdot \mathrm{cm}^{-1}\right) \times 10^{-7}$ & $E_{\mathrm{a}}(\mathrm{eV})$ & $\sigma_{\mathrm{ph}}\left(\mathrm{S} \cdot \mathrm{cm}^{-1}\right)$ \\
\hline $\mathrm{p}$ & $1.71,1.68,1.66,1.63$ & $5,48,107,233$ & $0.51,0.51,0.48,0.43$ & \\
$\mathrm{i}$ & 1.70 & $1 \times 10^{-4}$ & 0.80 & $1 \times 10^{-8}$ \\
$\mathrm{n}$ & 1.95 & $46 \times 10^{5}$ & 0.17 & \\
\hline
\end{tabular}

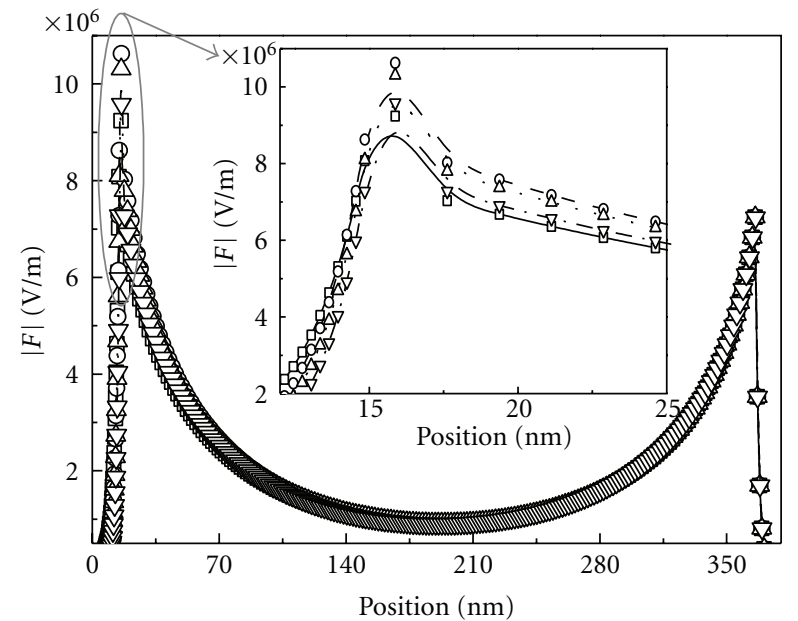

$$
\begin{array}{ll}
-\square-\text { Sample } 1 & \cdot \Delta \cdot \text { Sample } 3 \\
-\circ-\text { Sample } 2 & \nabla-\text { Sample } 4
\end{array}
$$

FIGURE 7: Electric field for a-Si thin film solar cell with different volume fraction of $\mathrm{B}_{2} \mathrm{H}_{6}$ in $\mathrm{SiH}_{4}$.

and resistance $\left(R_{1}\right)$. As can be seen from the model of the solar cell equivalent circuit model diagram Figure 1, that the depletion regions are in series, and parallel circuit is correlated with carrier generation and collection. Table 4 shows reduced capacitances at increased boron doping. It must be because of reduced capacitance at the $\mathrm{p} / \mathrm{i}$ interface depletion region. One of the possibilities that most likely can happen is an increased width of the depletion region with increased $\mathrm{B}_{2} \mathrm{H}_{6}$ doing of the p-type layer. At higher doping of the p-layer, more holes will be available in this layer that will diffuse through the $\mathrm{p} / \mathrm{i}$ interface and will create wider depletion region inside the i-layer. However for sample 2 the increase in capacitance has been observed. In spite of the lower doping-induced defects of sample 1, the higher $V_{\text {oc }}$ and $J_{\text {sc }}$ have been obtained on sample 2, because sample 1 has no sufficient electric field to collect of carriers.

The electric field profile in the $\mathrm{p}-\mathrm{i}-\mathrm{n}$ cell is plotted for different conditions in Figure 7. An increased defect leads to a reduced electric field in the $\mathrm{p} / \mathrm{i}$ interface, which results in poorer carrier collection from this part of solar cell. The poorer collection is associated with an increased recombination rate [13]. The electric field results can be determine from ASA simulation. Since most of the input parameters describe the optoelectronic properties of individual layers, described in Table 3, it is reasonable to use the experimental data of such individual layers.

Figure 8(a) shows the impedance spectrum from -0.1 to $-0.6 \mathrm{~V}$ in steps of $-0.1 \mathrm{~V}$ under reverse bias conditions. It was observed that the impedance spectrum is nearly semicircular in shape under the zero and reverse bias conditions, which implies that the equivalent circuit of the device consists of a single $R C$ network with a single time constant. The best-fit curves, obtained using $Z$-plot software, are also shown in the same figure. The obtained values of $R$ and $C$ are listed in Table 2. The radius of the semicircle increases with the increase in bias voltage as compared to that at zero bias demonstrating the bias dependence of resistance and capacitance values. Figure 8(b) shows the impedance spectrum under the forward bias (from 0.1 to $0.5 \mathrm{~V}$ ) conditions where in contrast to the reverse bias, opposite behavior was observed. Here the radius of the semicircle decreases with increasing positive bias from its maximum value at zero bias. Another noticeable feature is the deviation from a semicircular shape particularly in the high-frequency regime with biasing. However, no scatter of the data is seen in the lowfrequency regime.

From the impedance spectra, the p/i interface capacitance and resistance at different bias voltages were calculated. The $R C$ network is composed by two types of capacitances and resistances. They are diffusion and transition capacitances $\left(C_{\mathrm{d}}\right.$ and $\left.C_{\mathrm{T}}\right)$ and resistances $\left(R_{\mathrm{d}}\right.$ and $\left.R_{\mathrm{T}}\right)$, respectively. $C_{\mathrm{d}}$ and $R_{\mathrm{d}}$ are due to the gradient of the charge density inside the device and the bulk resistance of the space charge region, respectively. $R_{\mathrm{T}}$ is the resistance due to recombination of free carriers in the space charge region and $C_{\mathrm{T}}$ is the space charge layer capacitance. To understand the origin and value of capacitance at different bias voltages, " $C_{1}$ " is plotted against bias voltages in a logarithm scale for different diborane flow rate and is shown in Figure 9. It can be divided into three distinct regions, that is, one for $-0.6<V<-0.1 \mathrm{~V}$ and the other for $-1.0<V<0.4 \mathrm{~V}$ and other for $V>$ $0.4 \mathrm{~V}$. In region $\mathrm{I}$, that is, under reverse bias, the capacitance does not vary much with voltage which is the characteristic 


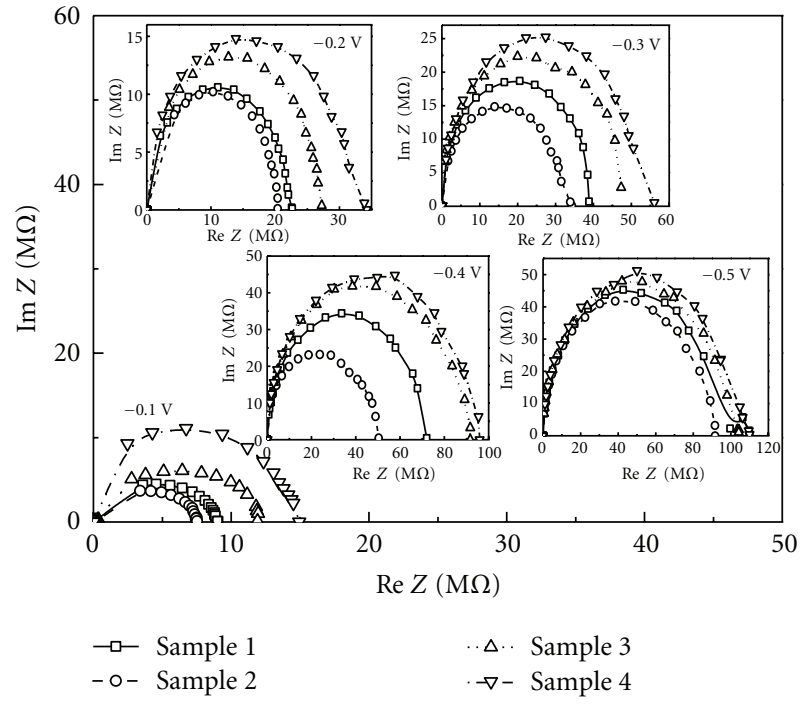

(a)

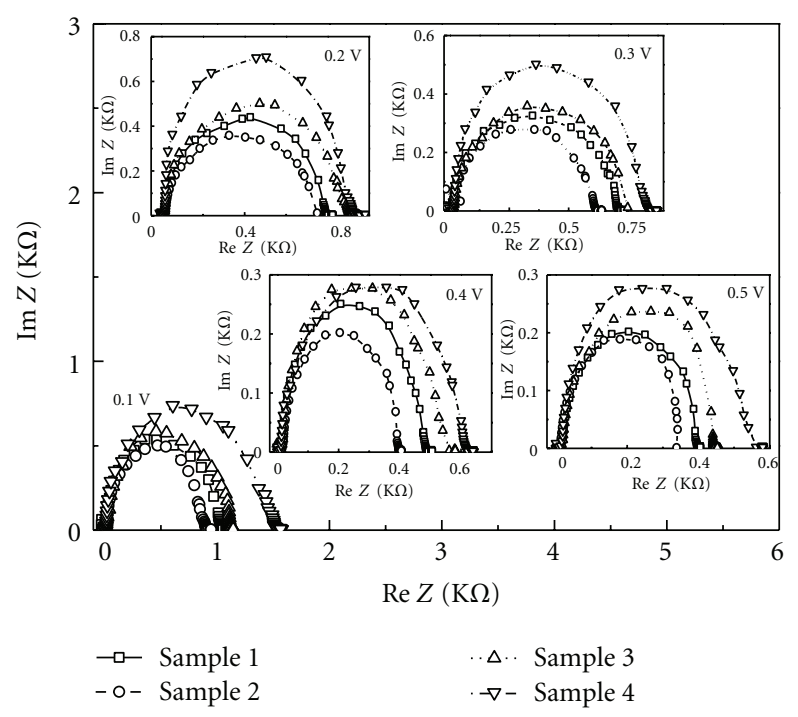

(b)

FIgURE 8: Cole-Cole plot of a-Si solar cell at different (a) reversed biases $(-0.1 \mathrm{~V} \sim-0.5 \mathrm{~V})$ and (b) forward biases $(0.1 \mathrm{~V} \sim 0.5 \mathrm{~V})$ conditions.

TABLe 4: Parameter of impedance spectra in a dark a-Si thin film solar cell with different volume fraction of $\mathrm{B}_{2} \mathrm{H}_{6}$ in $\mathrm{SiH}_{4}$ of $\mathrm{p}$ layer.

\begin{tabular}{lccccccccc}
\hline Sample & \multirow{2}{*}{$R_{\mathrm{c}}(\Omega)$} & $R_{1}(\Omega)$ & $C_{1}(\mathrm{nF})$ & $R_{2}(\mathrm{~K} \Omega)$ & $C_{2}(\mathrm{nF})$ & $R_{3}(\Omega)$ & $C_{3}(\mathrm{nF})$ & $R_{4}(\mathrm{~K} \Omega)$ & $C_{4}(\mathrm{nF})$ \\
\hline 1 & 8.75 & 201 & 248.7 & 21.1 & 0.29 & 18.1 & 24.5 & 19.4 \\
2 & 8.74 & 183 & 261.4 & 21.1 & 0.29 & 18.4 & 24.7 & 14.3 \\
3 & 8.75 & 458 & 200.0 & 21.1 & 0.29 & 18.1 & 24.7 & 39.7 & 227.4 \\
4 & 8.75 & 981 & 189.2 & 21.1 & 029 & 18.0 & 24.8 & 68.0 \\
\hline
\end{tabular}

TABLE 5: The values of diode ideality factor $(n)$ and built-in potential $\left(V_{\mathrm{bi}}\right)$ of solar cell with different diborane flow rate of p-type layers.

\begin{tabular}{lccc}
\hline Sample & Diode ideality factor $(n)$ & & Built-in potential $\left(V_{\mathrm{bi}}\right)$ \\
\hline 1 & Dark $I-V($ scr region $)$ & $C$ - $V$ (Region II) & 0.9929 \\
2 & 1.87 & 1.81 & 1.0529 \\
3 & 1.70 & 1.69 & 0.9609 \\
4 & 1.79 & 1.78 & 0.9199 \\
\hline
\end{tabular}

of the transition capacitance. We modified $C-V$ curve to $1 / C^{2}-V$ plot. The intercept of this plot on the abscissa gives the value of $\left(V_{\mathrm{bi}}-k T / q\right)$ which is shown in Table 5. By analyzing the second part, region II, of the $C-V$ curve in the forward bias which is dominantly diffusion capacitance that increases exponentially with bias voltage. It can be utilized for the determination of diode ideality factor. To verify this value, dark $I-V$ measurement has also been done on the device. From the slope of this curve, the diode ideality factor ( $n$ ) was calculated for cells with the different p-type layers, which is shown in Table 5. It shows that the diode ideality factor increases from 1.69 to 1.95 [14]. Region III occurs because of the junction capacitance. Compared to the static characteristics, the AC characteristics have same tendency and mechanisms of $\mathrm{p} / \mathrm{i}$ interface properties.

\section{Conclusions}

In amorphous silicon solar cells, p-type window layer strongly influences cell performance. As the different diborane flow rate, $\mathrm{p}$-type layer and $\mathrm{p} / \mathrm{i}$ interface properties change with cell performance. Mechanism of this phenomenon is explained by the changes in the three and fourfold coordinated boron atoms observed by XPS. The $\mathrm{p} / \mathrm{i}$ interface properties were obtained from the static/dynamic characteristics. The DC characteristics were measured from dark/illuminated current-voltage curves, and the AC characteristics were determined from the impedance spectroscopy. The impedance spectroscopy technique is used to measure the capacitance of amorphous silicon solar cell of different diborane flow rate in $\mathrm{p}$-type window layer. It has been shown 


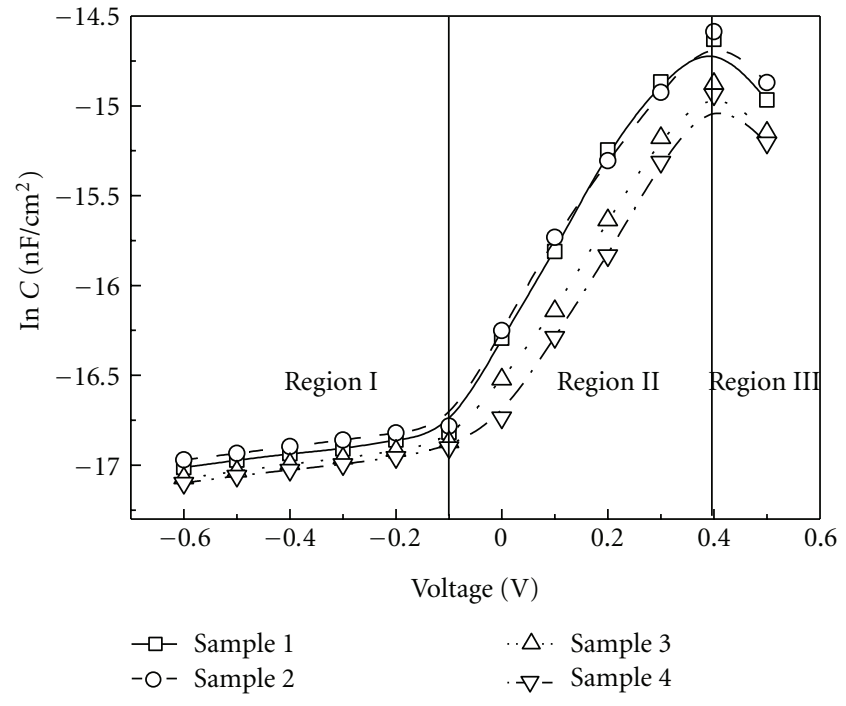

FIgURE 9: The measured capacitance $\left(C_{1}\right)$ as a function of bias voltage in the $\mathrm{p}-\mathrm{i}-\mathrm{n}$ structure.

that the capacitance associated with different biasing can be utilized to gather information related with device such as built-in potential and diode ideality factor. The diode ideality factor, obtained impedance spectroscopy, was estimated and found to be almost equal to the current-voltage data.

\section{Acknowledgments}

This work was financially supported by KRCF (Korea Research Council of Fundamental Science \& Technology) and SKKU (SungKyunKwan University) for National Agenda Project program. This research was also supported by the WCU (World Class University) program through the National Research Foundation of Korea funded by the Ministry of Education, Science and Technology (R31-2008000-10029-0). This work was supported by the New \& Renewable Energy Technology Development Program of the Korea Institute of Energy Technology Evaluation and Planning (KETEP) Grant funded by the Korea government Ministry of Knowledge Economy (20113020010010).

\section{References}

[1] K. S. Cole and R. H. Cole, "Dispersion and absorption in dielectrics I. Alternating current characteristics," Journal of Chemical Physics, vol. 9, pp. 341-351, 1941.

[2] A. S. Elwakil and B. Maundy, "Extracting the Cole-Cole impedance model parameters without direct impedance measurement," Electronics Letters, vol. 46, no. 20, pp. 1367-1368, 2010.

[3] T. Kazahaya and M. Hirose, "Coordination number of doped boron atoms in photochemically-deposited amorphous silicon studied by X-ray photoelectron spectroscopy," Japanese Journal of Applied Physics, vol. 25, no. 1, pp. L75-L77, 1986.

[4] R. A. Street, "Doping and the fermi energy in amorphous silicon," Physical Review Letters, vol. 49, no. 16, pp. 1187-1190, 1982.
[5] M. Stutzmann, "The doping efficiency in amorphous silicon and germanium," Philosophical Magazine B, vol. 53, no. 1, pp. L15-L21, 1986.

[6] S. Lee, S. Park, J. Park et al., "The effect of carrier injection stress on boron-doped amorphous silicon suboxide layers investigated by X-ray photoelectron spectroscopy," Japanese Journal of Applied Physics, vol. 50, no. 9, pp. 095801-095804, 2011.

[7] A. Asano and H. Sakai, "Improvement in the boron-doping efficiency of hydrogenated amorphous silicon carbide films using BF3," Journal of Non-Crystalline Solids, vol. 114, no. 1, pp. 268-270, 1989.

[8] F. H. Cocks, P. L. Jones, and L. J. Dimmey, "The optical band gap of hydrogenated amorphous-boron thin films: the effect of thermal treatment," Applied Physics Letters, vol. 36, no. 12, pp. 970-972, 1980.

[9] A. Yamada, J. Kenne, M. Konagai, and K. Takahashi, "Wide band-gap, fairly conductive $P$-type hydrogenated amorphous silicon carbide films prepared by direct photolysis; Solar cell application," Applied Physics Letters, vol. 46, no. 3, pp. 272274, 1985.

[10] Y. Lee, A. S. Ferlauto, Z. Lu et al., "Enhancement of stable open circuit voltage in a-Si: H P-I-N solar cell by hydrogen dilution of P/I interface regions," in Proceedings of the 2nd World Conference on Photovoltaic Solar Energy Conversion, pp. 940943, Vienna, Austria, 1998.

[11] C. H. Jeong, Y. B. Kim, S. H. Lee, and J. H. Kim, "Preparation of born-doped a-SiC:H thin films by ICP-CVD method and to the application of large-area heterojunction solar cells," Journal of Nanoscience and Nanotechnology, vol. 10, no. 5, pp. 3321-3325, 2010.

[12] R. Cottis and S. Turgoose, Handbook of Electrochemical Impedance and Noise, NACE international, Houston, Tex, USA, 1999.

[13] R. E. I. Schropp and M. Zeman, Handbook of Amorphous and Microcrystalline Silicon Solar Cells: Modeling, Materials and Device Technology, Kluwer Academy Publishers, Boston, Mass, USA, 1998.

[14] S. Kumar, P. K. Singh, G. S. Chilana, and S. R. Dhariwal, "Generation and recombination lifetime measurement in silicon wafers using impedance spectroscopy," Semiconductor Science and Technology, vol. 24, no. 9, Article ID 095001, 2009. 


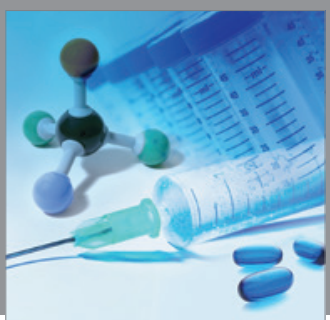

International Journal of

Medicinal Chemistry

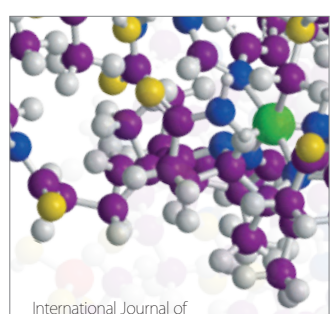

Carbohydrate Chemistry

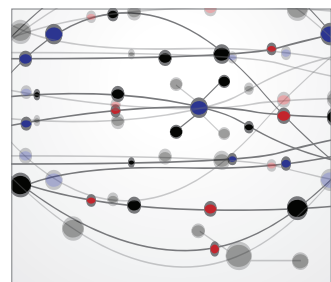

The Scientific World Journal
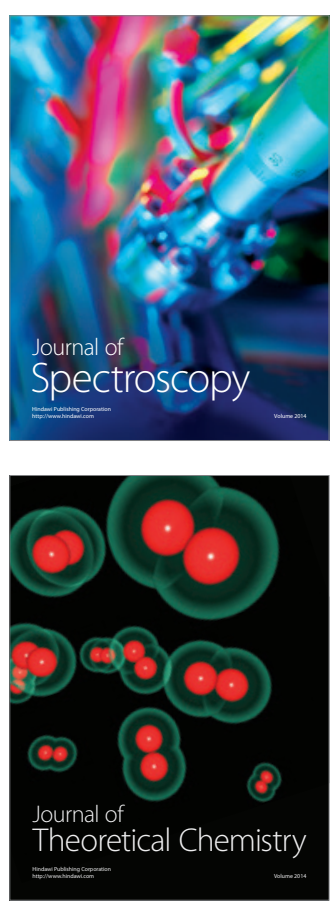
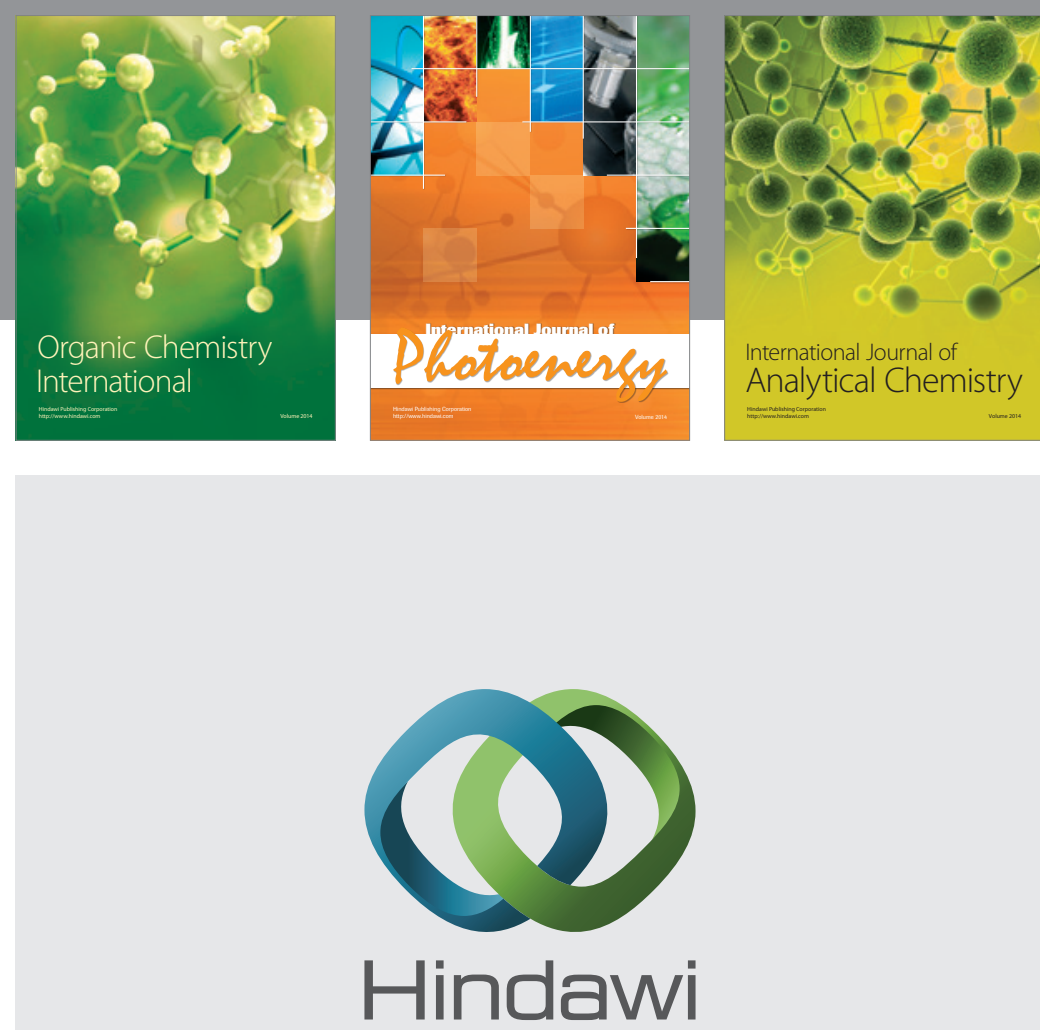

Submit your manuscripts at

http://www.hindawi.com
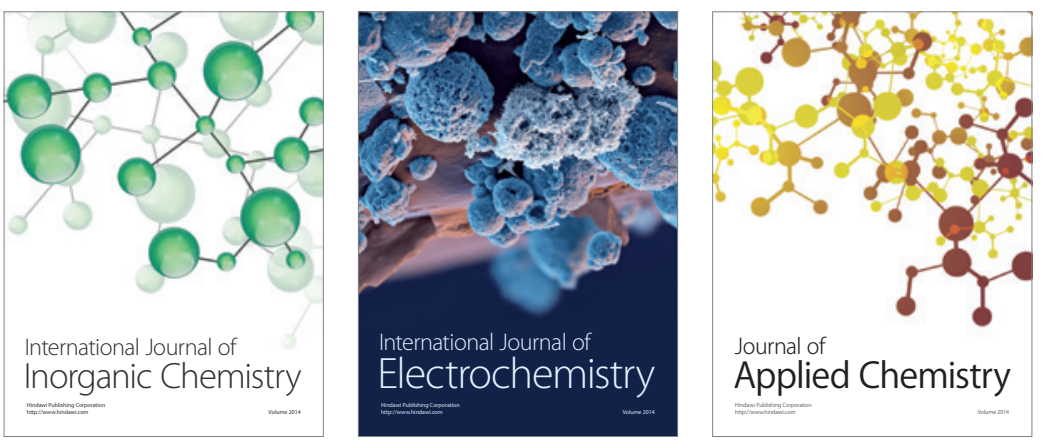

Journal of

Applied Chemistry
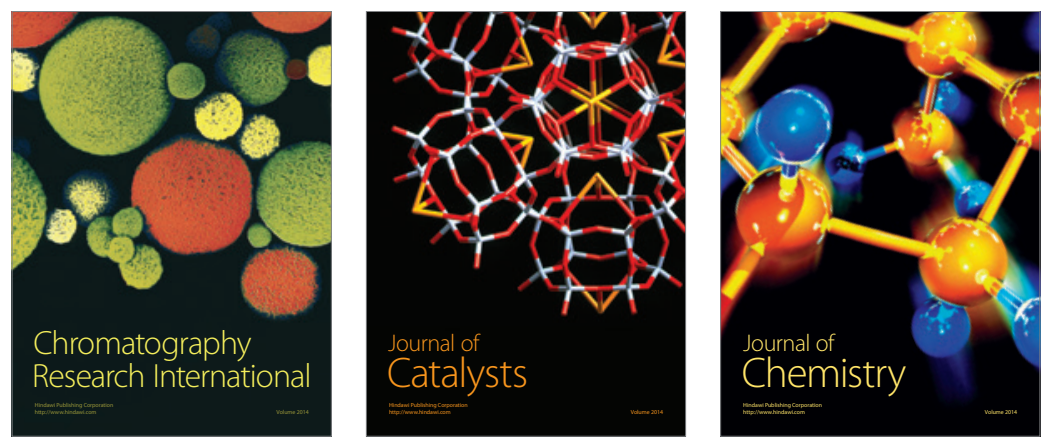
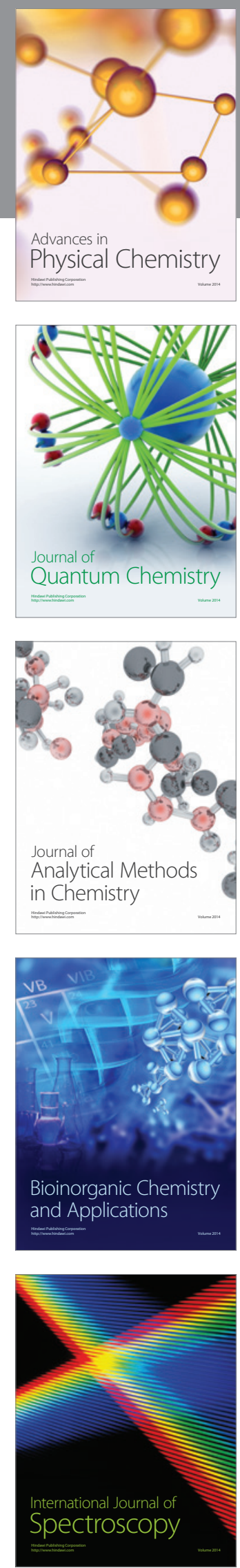